\title{
Rattling the cage and opening the door
}

\author{
Cecilia Heyes \\ All Souls College \& Department of Experimental Psychology \\ University of Oxford
}

\begin{abstract}
I share with Poulin-Dubois and with Sabbagh, Koenig and Kuhlmeier the conviction that more research is needed on the mechanisms supporting selective social learning in infants and children. However, my plea is more specific: for research that tests domain-specific hypotheses about mechanism against domain-general hypotheses derived from other fields of cognitive science. Many, but not all, of these alternative hypotheses relate to domain-general mechanisms of attention.
\end{abstract}

I am grateful to Poulin-Dubois (P-D) and to Sabbagh, Koenig and Kuhlmeier (SKK) for their constructive and very well-informed commentaries on my article 'When does social learning become cultural learning'. I found particularly helpful P-D's discussion of research on theory of mind that lay outside the scope of my article; SKK's elucidation of the domain-specificity hypothesis in terms of "gating"; and references in both commentaries to work by Kirkham, Sobel and others providing compelling evidence that psychological mechanisms can be specialised for social learning, not only by genetic evolution, but by learning (e.g. Tummeltshammer, Wu, Sobel \& Kirkham, 2014; Wu \& Kirkham, 2010).

P-D, SKK and I all agree that more research is needed on the mechanisms of selective social learning. They challenged my interpretation of some of the existing studies, and those challenges will be the main focus of this response. But first, some clarification: 1) I do not deny that developmentalists are already doing interesting work on the mechanisms of selective social learning. 
My pleas were for developmentalists to a) distinguish more clearly between hypotheses about mechanisms and functions, and b) integrate their work on mechanisms more fully with the rest of cognitive science by testing domain-specific against domain-general hypotheses. For me, a "working hypothesis" (SKK) is not working unless it is testable and tested against an alternative for which there is existing empirical support. 2) I think the tendency to conflate mechanistic and functional explanations is at least as strong in comparative as in developmental research on selective social learning (Heyes \& Pearce, 2014; Heyes, in press a). 3) In common with SKK, I believe that, in humans, some social learning is selective by virtue of what they call "top-down conceptual processing" and what I call "metacognition" (Heyes, in press b). The question is: when does this "cook-like" selective social learning begin to take hold, at 4-5 years of age, as I have proposed, or (much) earlier in development?

\section{Attention}

P-D thinks it is unlikely that the effects on head-touch copying reported by Zmyj, Daum, Prinz, Nielsen \& Aschersleben (2012) and Buttelmann, Zmyj, Daum \& Carpenter (2013) are due, as I suggested, to variation in the extent to which infants attended to the model's head. This certainly needs to be tested explicitly, in the ways I suggested in my article and in other ways, but I doubt that my attentional hypothesis is challenged by the studies P-D cited in this regard. For example, Gergely, Bekkering and Király (2002) did indeed report that head-touch copying declines when the model's hands are occupied, but Beisert, Zmyj, Liepelt, Jung, Prinz and Daum (2012) have shown that this is precisely because the hands occupied treatment distracts attention from the model's head movement. Furthermore, although Lewkowick and Hansen Tift (2012) found that infants stare more at the mouth rather than the eyes of someone speaking a foreign language, they did not report an effect of language spoken on attention to the whole of a speaker's head. 
Turning to research on model reliability, P-D agrees that learned predictiveness may account for some cases in which infants learn more from reliable models, but doubts that better learning of new words or of gaze-following to non-visible objects could be due to the associative mechanisms mediating learned predictiveness (Mitchell \& LePelley, 2010). I am not sure why she sees these cases as problematic. For example, in the word learning case (Brooker \& Poulin-Dubois, 2013), the infants had previously heard the unreliable model's voice making sounds that did not predict the object an infant would see when the infant turned towards the model. Therefore, on the learned predictiveness account, one would expect the infants subsequently to attend less to the sound of the unreliable model's voice (a variable that would not necessarily be reflected in looking time), and therefore to be less likely to associate a sound made by that voice with an object, i.e. to learn a new word from an unreliable than from a reliable model.

\section{Not only attention}

SKK were concerned about my interpretation of Williamson, Meltzoff \& Markham (2008). They believe my explanation of the effect reported in Experiment 1, in terms of heightened attention following an unpredicted outcome, is foiled by the results of Experiments 2 and 3, in which children encountered an unpredicted outcome after they saw the model. I discussed the results of Experiments 2 and 3 at some length in my article, arguing that they were due to associative actionoutcome learning by observation. This would be an inconsistent or capricious move on my part if I was claiming that all selective social learning is due to heightened attention following an unpredicted outcome, but I am not remotely tempted to make that "reductive" claim. Prediction error is at the heart of associative learning, but what SKK call "prediction error signalling" certainly does not exhaust the manifestations of associative learning, or, as it is sometimes called, "statistical learning". Consequently, whereas SKK are inclined to see any effect that cannot be explained by prediction error signalling as evidence of domain-specific conceptual processing, I think we need to 
look for other signs of associative learning - for example, of basic Pavlovian and instrumental learning - before jumping to that conclusion.

My article was concerned with research on selective social learning in which infants and children copy nonverbal behaviour. The studies that P-D cited as showing that selective trust is related to theory of mind in 4-5- year olds used verbal indicators of trustworthiness and/or verbal tests of selective social learning. Therefore, strictly speaking, they lie beyond my scope, but I found them very interesting. My hunch is that, in Western cultures, children begin to use domain-specific, "cook-like" social learning strategies, in addition to the domain-general "planetary" social learning strategies shared with other animals, at about 4-5 years of age, and that the domain-specific strategies are socially learned through language and theory of mind (Heyes, in press b). Evidence that (verbal) selective trust is related to theory of mind is, I think, entirely consistent with this broader picture.

I cannot deny P-D's witty allegation that my article was "rattling the developmental psychologist's cage". After all, I was once a rat-runner, albeit long ago, and, as P-D pointed out, this is not the first time I have tried to stimulate change in a research field by questioning the interpretation of some cherished studies. Such an effort would have no chance of success if it was not, at some level, irritating. But I do try to be constructive; to recommend new methods and hypotheses, and thereby, not only to rattle the cage, but also to open the door.

\section{References}

Beisert, M., Zmyj, N., Liepelt, R., Jung, F., Prinz, W., \& Daum, M. M. (2012). Rethinking 'rational imitation' in 14-month-old infants: A perceptual distraction approach. PloS one, 7(3), e32563.

Brooker, I., \& Poulin-Dubois, D. (2013b). Is a bird an apple? The effect of speaker labeling accuracy on infants' word learning, imitation, and helping behaviors. Infancy, 18, E46-E68. 
Buttelmann, D., Zmyj, N., Daum, M., \& Carpenter, M. (2013). Selective imitation of in-group over out-group members in 14-month-old Infants. Child Development, 84, 422-428.

Gergely, G., Bekkering, H., \& Király, I. (2002). Rational imitation in preverbal infants. Nature, $415,755$.

Heyes, C. (in press a). Blackboxing: social learning strategies and cultural evolution. Philosophical Transactions of the Royal Society, $B$.

Heyes, C. (in press b). Who knows? Metacognitive social learning strategies. Trends in Cognitive Sciences.

Heyes, C., \& Pearce, J. (2015). Not-so-social learning strategies. Proceedings of the Royal Society B: Biological Sciences, 282, 20141709.

Lewkowicz, D.J, \& Hansen-Tift, A.M. (2012). Infants deploy selective attention to the mouth of a talking face when learning speech. Proceedings of the National Academy of Sciences, 109, 1431-1436.

Mitchell, C. J., \& Le Pelley, M. E. (2010). Attention and associative learning: from brain to behaviour: Oxford University Press.

Poulin-Dubois, D. (2016). Rattling the developmental psychologist's cage? Developmental Science.

Sabbagh, M. A., Koenig, M. A. \& Kuhlmeier, V. A. (2016). Conceptual constraints and mechanisms in children's selective learning. Developmental Science.

Tummeltshammer, K. S., Wu, R., Sobel, D. M., \& Kirkham, N. Z. (2014). Infants track the reliability of potential informants. Psychological Science, 25, 1730-1738.

Williamson, R. A., Meltzoff, A. N., \& Markman, E. M. (2008). Prior experiences and perceived efficacy influence 3-year-olds' imitation. Developmental Psychology, 44, 275.

Wu, R., \& Kirkham, N. Z. (2010). No two cues are alike: Depth of learning during infancy is dependent on what orients attention. Journal of Experimental Child Psychology, 107, 118-136. 
Zmyj, N., Daum, M. M., Prinz, W., Nielsen, M., \& Aschersleben, G. (2012). Fourteen-month-olds' imitation of differently aged models. Infant and Child Development, 21, 250-266. 